\title{
Experimental Study on Structural Health Monitoring of Carbon Fibre Reinforced Concrete Beam
}

\author{
Bharathkumar. S1, Jenifar Monica. J² \\ ${ }^{1}$ PG Student, Department of Civil Engineering, Sona College of Technology, Salem, Tamilnadu, India \\ ${ }^{2}$ Assistant Professor, Department of Civil Engineering, Sona College of Technology, Salem, Tamilnadu, India
}

\begin{abstract}
The main objective of this project is to monitor the structural health of carbon fibre reinforced concrete beam by using sensor embedded in it. The problem that has been identified is there is no standard method of structural health monitoring for carbon fibre reinforced structures. Carbon fibre reinforced concrete is those structures in which the steel reinforcement is replaced by carbon fibre mesh. The grade of concrete that is used is M25 with OPC53 cement. 6mm size of coarse aggregate and manufacturing sand. Casting of prism and beam specimens is done by placing the carbon fibre mesh in box type. The carbon fibre reinforced concrete is the structure which the steel reinforced is replaced by carbon fibre mesh. In this study, the casting the prism and beam specimen is done by placing the carbon fibre mesh. The concept of design is not only to monitor strain but also act as a structural strengthing mechanism in target. The sensor that is used thermocouple, which is used for measuring the internal concrete temperature. The temperature of carbon fibre reinforced concrete beam during loading is measured. To arrive, the relation between internal concrete temperature and load applied. To monitor the structural behaviour of carbon fibre reinforced concrete beam during structural health monitoring system. The temperature range can be fixed in the sensor for continuous monitoring of structure .While the system can be programmed to ring an alarm. When temperature exceeds the specified limit.
\end{abstract}

Key words: Carbon fibre reinforcement, structural health monitoring, Thermocouple sensor, Temperature

\section{INTRODUCTION}

Structural health monitoring refers to process of implementing a damage detection and characterization strategy for the structures. A typical health monitoring system is composed of a network of sensors that measure the parameters relevant to the state of the structure and its environment, such as temperature, stress, delamination, strain, vibration, and humidity To properly manage civil infrastructure, its condition, or serviceability, needs to be assessed. Many variables can be monitored and used for the assessment. Tunnels are being monitored for traffic accidents and air quality. The Urgent Earthquake detection and Alarm System Measurement and proper data processing are expected to give a reasonable assessment of serviceability can then be improved based on the assessment. Sensing physical quantities in detail offers the potential to better estimate structural conditions. For river bank protection, for instance, water level may be monitored and the associated load estimated. Precipitation rate and groundwater level are an important indicator to predict slope failure.. Structural condition assessment is, however, not always straightforward; such is the case in Structural Health Monitoring (SHM) of buildings, bridges, and towers

\subsection{Health Assessment of Engineered Structure.}

The concept is widely applied to various forms of infrastructure, as countries all over the world entre into greater period of construction of various infrastructure bridges to skyscrapers. Especially when damages to structure are concerned, note that there are stages of increasing difficulty that required the knowledge of previous stages, namely;

A) Locating the damage

B) Quantifying the severity the damage

C) Detecting the existence of damage on the structure

D) Identifying the types of damage

\subsection{Textile reinforcement}

Textile reinforced concrete is a type of reinforced concrete in which the usual steel reinforcing bars are replaced by textile material. Materials with high tensile strength, with negligible elongation properties are reinforced with woven or non-woven fabrics. . The fibres used for making the fabric are of high tenacity like jute, glass, fibre, Kevlar, polypropylene, polyamides (Nylon) etc. Textile reinforced concrete is generally thinner than traditional steel reinforced construction is 100 to $300 \mathrm{~mm}$ thick. TRC is much thinner due to an extra protective layer of concrete that is not needed for its design.

\section{MATERIAL PROPERTIES}

In this study, the following materials are used and testing of materials such as materials cement, M-sand and Coarse aggregate to determine the following properties fineness of cement, consistency and initial setting time of cement, specific gravity, fineness modulus of Fine aggregate and Coarse aggregate.

\subsection{Concrete materials}

2.1 .1 cement

Ordinary Portland cements (OPC) the basic Portland cement and is best suited for use in general concrete construction. It is of three types 33 grade, 43 grades and 53 grades. In this study 53 grade of cement is used. 
Table 1 physical properties of 53 grade ordinary Portland cement.

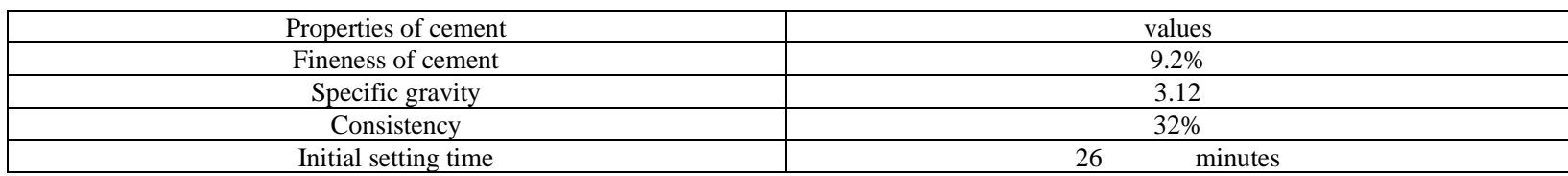

\subsection{Fine aggregate}

According to IS 383:1970 the fine aggregate is being classified into four different zones that is zone-I, zone-II, zone-III and zone-IV.Manufactured sand is crushed aggregates produced from hard granite stone which is cubically shaped with grounded edges, washed and graded with consistency to be used as a substitute of river sand. Tested conducted on fine aggregate are specific gravity, fineness modulus and water absorption.

Table 2 physical properties of manufactured sand

\begin{tabular}{|c|c|}
\hline Properties of fine aggregate & values \\
\hline Specific gravity & 2.55 \\
\hline Fineness modulus & 2.81 \\
\hline Grading zone & II \\
\hline
\end{tabular}

\subsubsection{Coarse aggregate}

The coarse aggregate is the strongest and the least porous component in concrete. The optimum size of coarse aggregate used for carbon fibre mesh with $5 \mathrm{~mm}$ grid size was found to be $20 \mathrm{~mm}$ and hence it was adopted. The specific gravity test, fineness modulus test and water absorption test are conducted on coarse aggregate

Table 3 physical properties of coarse aggregate

\begin{tabular}{|c|c|}
\hline Properties of coarse aggregate & Values \\
\hline Specific gravity & 2.55 \\
\hline Fineness modulus & 6.71 \\
\hline Water absorption & $1.45 \%$ \\
\hline
\end{tabular}

\subsubsection{Carbon fibre mesh}

To improve the tensile reinforcement high strength fabrics made of textile Reinforcement can be used. The multifilament yarn made of carbon fibre mesh was used in study. Carbon fibre mesh was used as reinforcement and other materials properties are listed below

Table 4 properties of carbon fibre mesh

\begin{tabular}{|c|c|}
\hline \multicolumn{2}{|c|}{ Carbon fibre mesh } \\
\hline Name & $1762 \mathrm{~N} / \mathrm{mm}^{2}$ \\
\hline Tensile strength & $1.81 \%$ \\
\hline Elongation of fibre & $8200 \mathrm{~N} / \mathrm{mm}^{2}$ \\
\hline Modulus of elasticity & $1 \mathrm{~mm}$ \\
\hline Diameter of fibre & $5 \mathrm{~mm} \times 5 \mathrm{~mm}$ \\
\hline Size of grid & \\
\hline
\end{tabular}

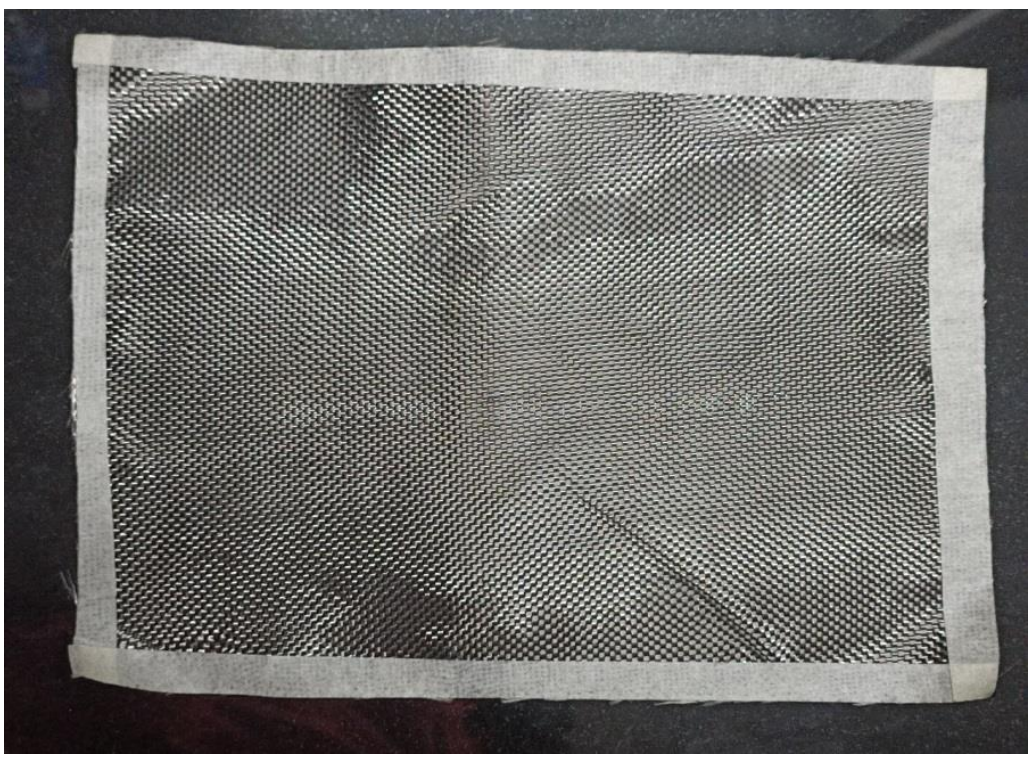

Fig1 carbon fibre mesh 


\subsection{Thermocouple sensor}

Thermocouple is an electrical device consisting of two dissimilar electrical conductors forming electrical junctions at differing temperatures. A thermocouple produces a temperature-dependent voltage as a result. The voltage generated at a single junction of two different types of wire is what is of interest as this can be used to measure temperature at very high and low temperatures. The magnitude of the voltage depends on the types of wire being used. Generally, the voltage is in the microvolt range and care must be taken to obtain a usable measurement.

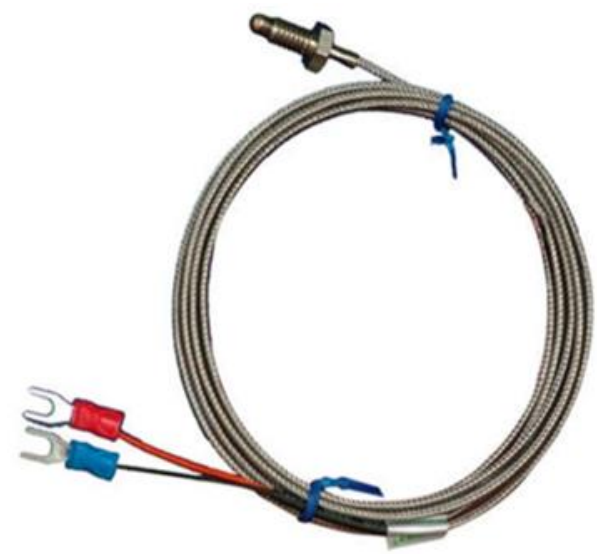

\subsection{Concrete}

Fig2 thermo couple sensor

Table 5 shows mix proportion of concrete for compressive strength of $25 \mathrm{MPa}$.

Table 5 mix proportioning of concrete

\begin{tabular}{|c|c|}
\hline Components & Quantity \\
\hline Water & 220.48 litres \\
\hline Cement & $400.87 \mathrm{~kg} / \mathrm{m}^{3}$ \\
\hline M sand & $782.62 \mathrm{~kg} / \mathrm{m}^{3}$ \\
\hline Coarse aggregate & $922.64 \mathrm{~kg} / \mathrm{m}^{3}$ \\
\hline
\end{tabular}

\section{EXPERIMENTAL INVESTIGATION}

\subsection{Test specimen}

Three specimens of $1200 \mathrm{~mm} \times 150 \mathrm{~mm} \times 200 \mathrm{~mm}$ were casted with thermocouple sensor embedded at the middle and one third of the prism, along the transverse direction. Carbon fibre mesh placed in box like sandwich shape having cover of $15 \mathrm{~mm}$ on all sides.

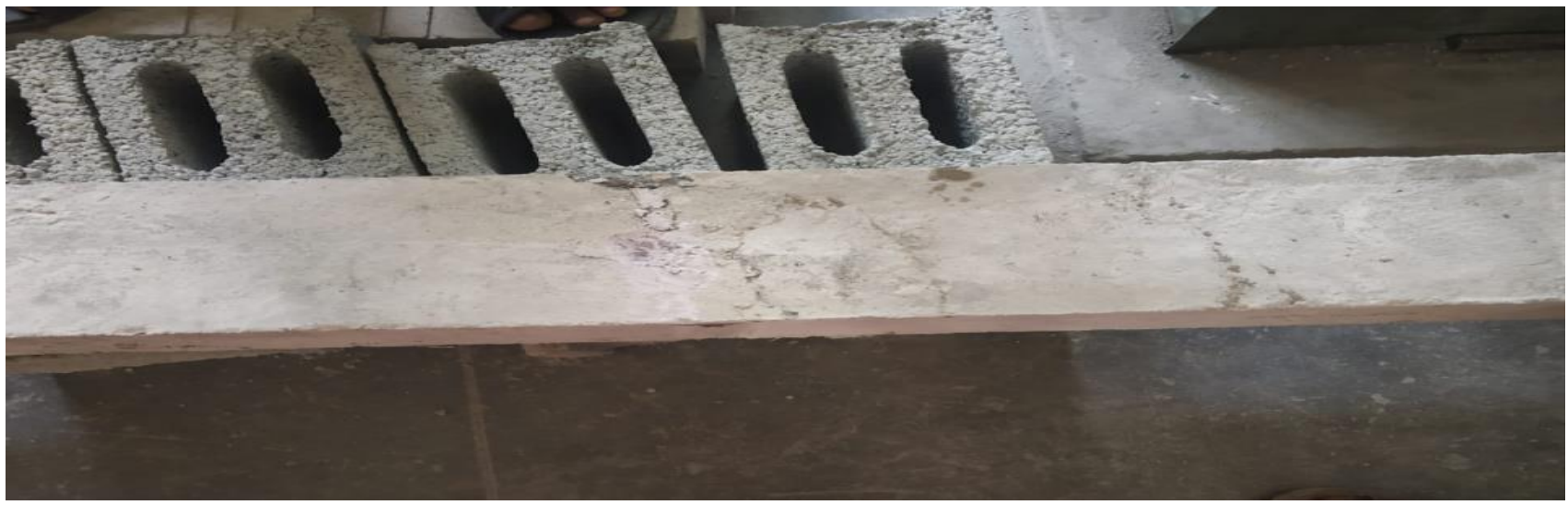

\subsection{Experimental setup and loading}

Fig3 Test Specimen

The 3 prisms were tested to failure in a two point loading system with a clear span of $50 \mathrm{~mm}$ and effective span $400 \mathrm{~mm}$. the load was applied using the universal testing machine. Two dial gauges were used to measure deflection. The testing of prism was carried out in universal testing machine of $1000 \mathrm{KN}$ load capacity. The load was applied in specimen and corresponding change in temperature was noted. 

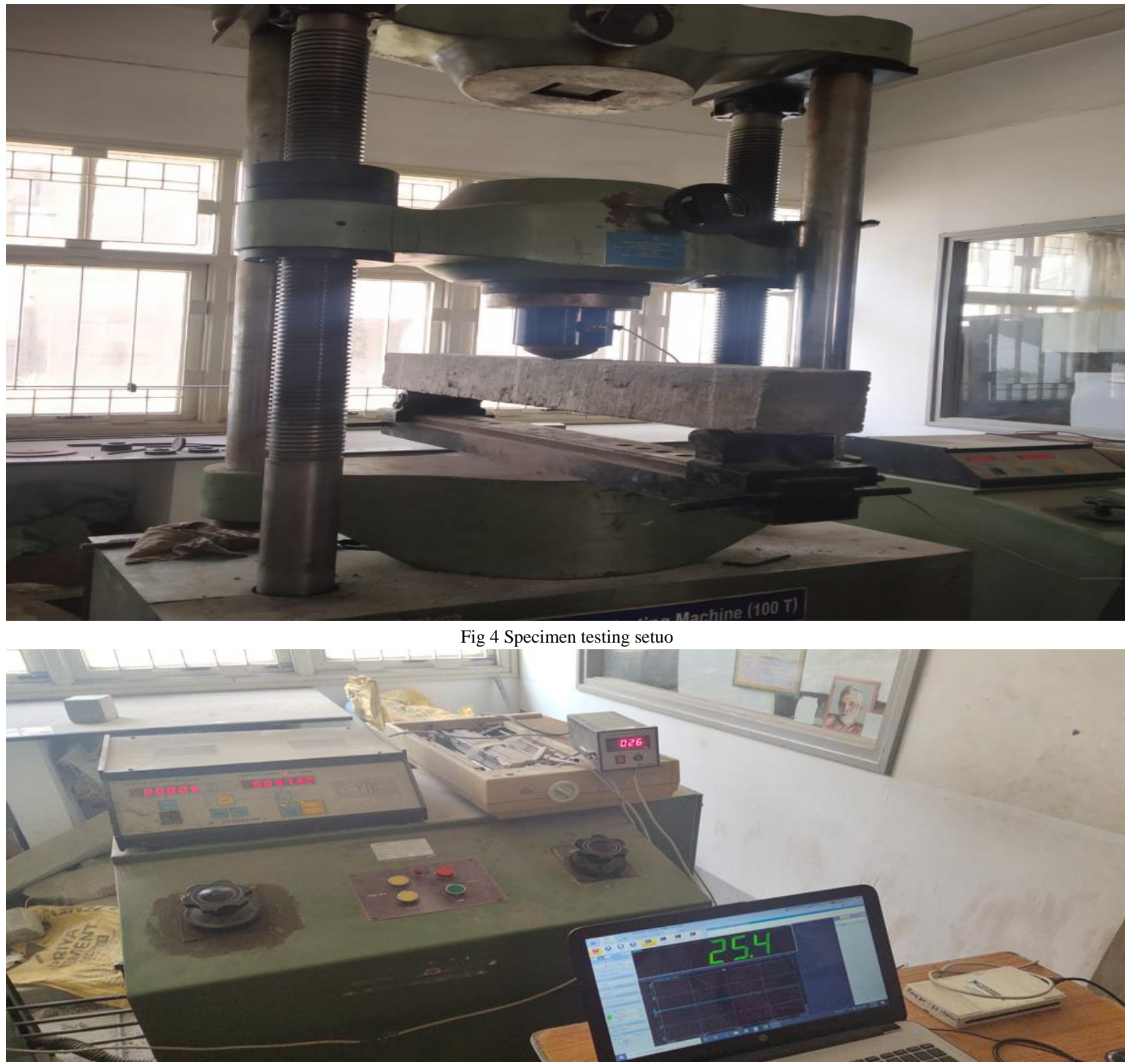

Fig 5 Monitoring Setup

\subsection{Result and discussion.}

For the applied load corresponding change in temperature was noted. The load change for carbon fibre reinforced concrete at one third and mid distance. The relation between internal concrete temperature and applied load for specimens has been arrived as below. And for every change in load the corresponding change in temperature has noted.

Relation arrived

$$
\begin{gathered}
Y=-31.818 x^{2}+1804.1 x-25555 \\
x-\text { Temperature }\left({ }^{\circ} \mathrm{c}\right) \\
y-\text { Load }(\mathrm{KN})
\end{gathered}
$$

\section{CONCLUSION}

From the testing, the internal load temperature of the concrete also increases which can be used as means of warning and it can be inferred that with increases in loading. From the relation it is known that temperature variation remains the same for various specimens of same kind. Further studies and experiment have to made different specimens and different sizes to arrive global relation between the temperature and load thereby make health monitoring system more economical with thermocouple sensors.

\section{REFERENCES}

[1] CatherineG. Papanicolaous, and thanasis c.trintafillou "Textile reinforced mortor versus FRP confinement in reinforced concrete columns (2007)

[2] Bernhard Roth and Reinhard helbig, 'structural health monitoring using textile reinforcement structures with integrated optical fibre sensors'(2017)

[3] Chandramouli 'srinivasa rao strength properties of glass fiber concrete'(2010)

[4] Jens Hartig, Ulrich Haubler-Combe, Kai Schicktanz Influence of bond properties on the tensile behaviour of textile reinforced concrete (2008) 
[5] Kort Bremer ,Frank Weigand, Yulong Zheng, Lourdes Shanika Alwis, Reinhard Helbig and Bernhard Roth . Structural health monitoring using textile reinforced structure with integrated optical fibre sensors(2012)

[6] Dionysios.A. Bournas, Panagiota V. Lontou, New Hybrid Material Of Textile Reinforced Concrete And Glass Fibre Reinforced Plastic"(2007)

[7] Yiska Goldfeld, Oded Rabinovitch, Till Quadflieg, Thomas Gries Sensory Carbon Fibre Based Textile Reinforced Concrete For Smart Structures(2015)

[8] Marko Butlera, Viktor Mechtcherinea Strain rate effect on the tensile behaviour of textile-reinforced concrete under static and dynamic loading(2011)

[9] Martina Drdlova , Rene Cechmanek Comparison of tensile behaviour of polypropylene, aramid and carbon fibre reinforced cementitious composite at high strain rate loading(2009)

[10] Laxman chavan, S.S.Injaganeri Comparison of compressive and split tensile strength of aramid fibre reinforced concrete with convention concrete(2018)

[11] Manjusha Ramakrishnan, Ginu Rajan , Yuliya Semenova and Gerald Farrell Overview of fibre optic sensor for strain/temperature sensing application in composite material(2016) 